From the *Department of Child Health, **Department of Pathology, ***Department of Radiology, Medical School, Airlangga University, Surabaya.

\title{
A Child with Nephrotic Syndrome and Late Congenital Syphilis (Case Report)
}

\author{
by \\ LILLY ZULKARNAIN - MALAON*, R.H. SARDJITO DJOJO- \\ HADIPRINGGO*, I WAJAN GIRI**, MOCH. SOEBAGYO \\ SINGGIH***
}

Among the diseases considered to be the possible etiologic causes of nephrotic syndrome are renal vein thrombosis and congenital syphilis (Hill et al., 1972; Strauss and Welt, 1971). Renal involvement in syphilis has been recognized for at least 150 years. Scattered reports of congenital syphilis presenting as nephrotic syndrome or nephritis in children have appeared in the medical literature (Bhohrade et al. 1971; Papaioannou et al., 1961).

Underneath is a report of a case with nephrotic syndrome that might be due to congenital syphilis.

\section{Case Report}

A 9-year-old Indonesian girl was admitted to the Dr. Soetomo Hospital, Surabaya, on September 15, 1973. The patient, the eldest of five children was the produat of an uneven-

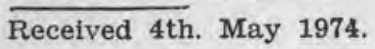

tful pregnancy and delivery. All other children were considered to be normall throughout their neonatal period and infancy except for this patient who had a chronic and severe rhinitis in infancy. On admission the patient denied a past history of renal disease, edema, hematuria, bee stings, malaria, diabetes, toxin exposure, syphilitic eruption or framboesia.

Three months prior to admission she had developed a rapid succession of enlargement of her abdomen, oliguria, and the passage of cloudy and reddish urine. She was then admitted to a small hospital in Tulung Rejo. Because there was no improvement after one month therapy and hospitalization she was referred to Surabaya.

On admission she weighed $19.6 \mathrm{Kg}$. The blood pressure was $140 / 110$, the 


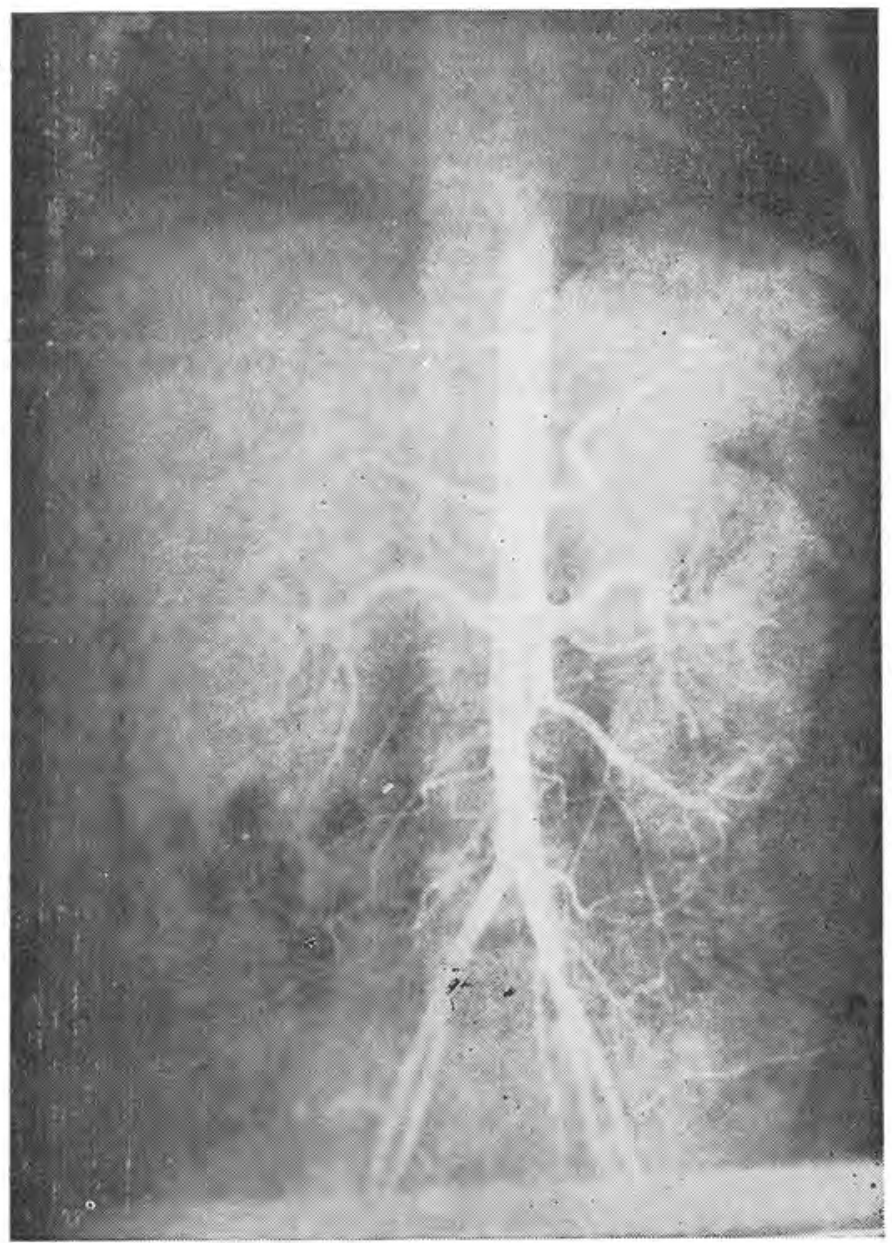

FIG. 1 : Renal Arteriography showed an elongation of the calyx in the upper pole of the right kidney 


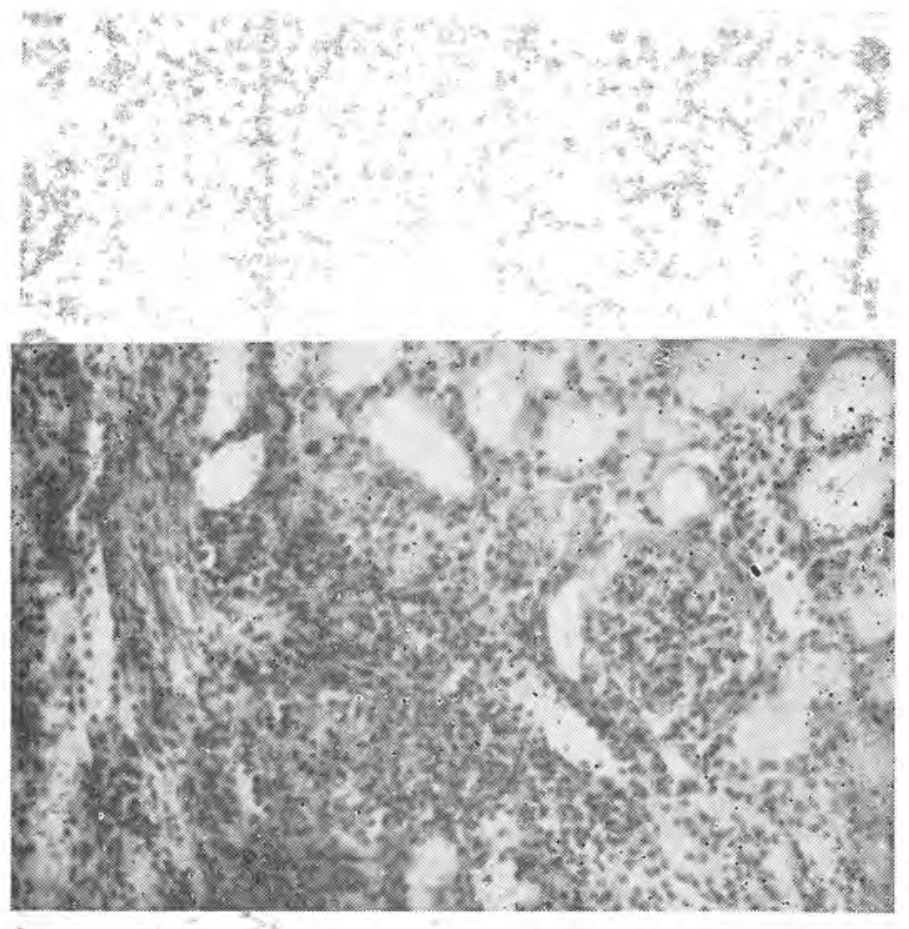

FIG. 2 ? Histo-pathalogical examination showed proliferati- ve glomerulanephritis.

if

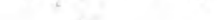


pulse rate 120 per minute, and the respiratory rate was 24 per minute. Examination of the face disclosed only a saddle nose. There were no abnormalities in the eyes, ears, and teeth. The heart and lungs were normal. The liver was $5 \mathrm{~cm}$ below the costal margin palpable, there was no splenomegaly. Ascites and umbilical hernia were present.

The urine had a specific gravity of 1020 , it contained $4+$ protein with the excretion of 15 grams a day. No reducing substances were present. The urine sediment disclosed 3 to 4 leukocytes, many erythrocytes and 2-3 granular casts per high power field.

Oval fat bodies were also present. The patient's hemoglobin was 11.8 gm per $100 \mathrm{ml}$, hematocrit $39 \%$. The total leukocyte count was 15.000 per cubic millimeter with a differential count as follows: easinophils $1 \%$; band forms $3 \%$; neutrophils $43 \%$; lymphocytes $52 \%$; monocytes $1 \%$; The platelet count was normal. Bleeding and clotting time were also normal. The serum cholesterol was 385 $\mathrm{mg} / 100 \mathrm{ml}$; creatinine $0.92 \mathrm{mg} / 100$ $\mathrm{ml}$; blood urea nitrogen $18.6 \mathrm{mg} / 100$ $\mathrm{ml}$; serum sodium $151 \mathrm{mEq} / 1$; chloride $97 \mathrm{mEq} / 1$; Potassium $7.03 \mathrm{mEq} /$ 1; $\mathrm{CO}_{2} 21 \mathrm{mM} / 1$. The serum albumin was $1.08 \mathrm{gm} / 100 \mathrm{ml}$, globulin 2.94 $\mathrm{gm} / 100 \mathrm{ml}$ with a total of $4.02 \mathrm{gm} /$ $100 \mathrm{ml}$. Blood examination for malaria and LE cells were negative.

Electrophoresis of serum protein produced the following results: albumin
$19.9 \%$, alpha- 1 globulin $6.1 \%$, alpha2 globulin $52.7 \%$, beta globulin $13.7 \%$ and gamma globulin $7.6 \%$. Electrophoresis of the urine gave the following results: albumin $71.7 \%$, alpha-1 and alpha-2 globulin together $9.2 \%$, beta globulin $11.1 \%$ and gamma globulin $8 \%$.

Repeated urine cultures were sterile. The serologic test for syphillis (VDRL) was reactive at a dilution of 1 : 16 and the Wassermann test was positive. Serologic studies for syphilis in the rest of the family revealed the mother to be positive and the father negative. Examination of the patient's other siblings was refused by the parents. Roentgenograms of the long bones and chest disclosed no abnormalities.

Renal arteriography, performed after an intravenous pyelogram, showed an elongation of the calyx in the upper pole of the right kidney. It only revealed the presence of large kidneys which is a usual finding in nephrotic syndrome. (see figure No. 1).

A percutaneous renal biopsy was prepared for bright field microscopy. The findings were as follows: "Mesangial proliferations are seen, some glomeruli are partially, and many completely obliterated. There are albumin casts in the lumen of the tubuli and cloudy swelling of the tubular epithelial cells. The interstitial tissues are slightily infiltrated with polymorphonuclear cells. The pathological diagnosis is proliferative 
glomerulonephritis". (see figure No. 2).

The clinical diagnosis were nephrotic syndrome and late congenital syphilis. The patient received penicillin, aldactone, reserpine and preanisone. After two months of therapy the VDRL was reactive only at a dilution of $1: 8$ and after three months at a dilution of $1: 2$.

Subsequent physical and urine examination after two months of therapy gave no significant improvement. Prednisone was then changed into endoxan and the patient was followed up in the out patient clinic. After three weeks with endoxan there were still no improvements. Further follow-up studies were not possible because the patient did not come back.

\section{Discussion}

The diagnosis of nephrotic syndrome in this patient was based on the presence of ascites, hypercholesterolemia, massive proteinuria, hypoproteinemia, oval fat bodies in the urine and the characteristic findings in serum electrophoresis. Late congenital syphilis was diagnosed on account of the clinical finding of a saddle nose and the positive serologic tests for syphilis (STS). Other diseases which give false positive STS can be excluded because they never give a VDRL test reactive more than $1: 4$ (Willcox, 1964).

Two clinical forms of renal disease have been described in congenitall syphilis: nephrotic syndrome and nephritis. Syphilitic children may have features of both diseases. In infants with congenital syphilis without renal symptoms, the kidney may show only a mild increase in interstitial connective tissue. Interstitial inflammation with a large number of plasma cells and lymphocytes may be seen (Braunstein et al., 1970; Hill et al., 1972). Treponema may be demonstrated in the interstitium, in the tubular lumens, and among the tubular epithelial cells (Hill et al., 1972).

In infants with renal symptoms one may find swelling and proliferation of the endotheliall and epithelial cells, glomerular and initerstitial inflammation, and basement membrane thickening (Falls et al., 1965; Hill et al., 1972). Many workers have described electron microscopic and immunofluorescent studies on the kidneys of patients with syphilis and nephrotic syndrome. Mesangial cell proliferation was noted in the glomeruli, dense subepithelial hump-like electron deposits were seen in the basement membrane, and seen by immunofluorescent microscopy these deposits corresponded to granular deposition of gamma gllobulin demonstrated subepithelially along the basement membrane (Bhohrade et al., 1971; Braunstein et al., 1967; Falls et al., 1965; Hoyer et al., 1967; Me Donald and Bante, 1963; Strauss and Welt, 1971). That was why they suggested that syphilitic nephrosis was an immune 
deposit disease (Braunstein et al., 1970; Mc Donald et al., 1971).

This deposition of immunoglobulins and complements would result in damage to the basement membrane and the subsequent development of the nephrotic syndrome, An attempt to demonstrate treponemal antigen in the glomerular deposit with antitreponemal human serum (VDRL-positive) was unsuccessful. The patient presented above fulfills the accepted criteria for nephrotic syndrome and late congenital syphilis.

It was difficult to prove whether these diseases had a causal relationship because we do not have either an electron or an immunofluorescent microsecpe.

In most cases rapid recovery of the nephrotic syndrome due to syphilis was reported following anti-syphi- litic therapy (Bhohrade et all, 1971; Mc Donald and Bante, 1963), but in another literature it was stated that the child's prognosis for recovery would appear to depend on the severity of the renal lesion (Mc Donald et al., 1971). In our case, if there was a causal relationship between these two diseases, the non-satisfactory result of antisyphilitic therapy upon the renal disease, would have been due to the chronic renal lesion as was seen in the renal specimen.

\section{Summary}

Clinical and renal morphologic studies have been reported on a 9-yearold Indonesian girl with nephrotic syndrome and late congenital syphilis. The possibilities of a relationship between these itwo diseases have also been discussed.

\section{REFERENCES}

1. BHOHRADE, M.S.; CARAG, H.B.; LEE, H.J.; POTTER, E.V. and DUNEA, G.: Nephropathy of Secondary Syphilis. J. amer. med. Ass. $216: 1159$ (1971).

2. BRAUNSTEIN, G.D.; LEWIS, E.J.; GALVANEK, E.G., HAMILTON, A. and BELL, W.R.: The Nephrotic Syndrome Associated with Secondary Syphilis. Amer. J. Med. 48 : 643 (1970).

3. FALIS, W.F.; FORD, K.L. and A.STHWORTH, C.T.: The Nephrotic Syndrome in Secondary Syphilis. Report of a case with renal biopsy findings. Ann. intern. med. 63 : 1047 (1965).
4. HILL, L.L.; SINGER, D.B.; FALLETTA, J. and STASNEY, R.: The Nephrotic Syndrome in Congenital Syphilis: An Immunopathy. Pediatries $49: 260$ (1972).

5. HOYER, J.R.; MICHAEL, A.F.; GOOD, R.A. and VENIER, R.R.: The Nephrotic Syndrome in Early Infancy. Clinical morphologic and immunologic studies of four infants. Pediatrics $40: 233$ (1967).

6. Me DONALD, C.J. and BANTE, A.W.: Acute Syphilitic Nephrosis. Arch. intern. Med. 111 : 228 (1963).

7. MC DONALD, R.; WIGGELINKHUIZEN, J. and KASCHULA, R.O.C.: The 
Nephrotic Syndrome in Very Young Infants. Amer. J. Dis. Child. 122 : 507 (1971).

8. PAPAIOANNOU, A.C.; ASROW G.G. and SCHUNCKMELL, N.H.: Nephrotic Syndrome in early infancy as a manifestation of Congenital Syphilis. Pediatrics 27 : 636 (1961).
9. STRAUSS, M.B. and WELT, L.G. : Diseases of the Kidney. 2nd Ed, pp. 503 (Little Brown, Boston 1971).

10. WILLCOX, R.R.: Textbook of Venereal Diseases and Treponematoses. 2nd Ed. pp. 276 (William Heinemann med. Books, London 1964).

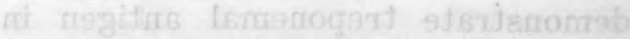

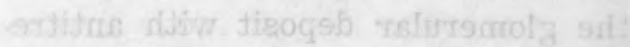

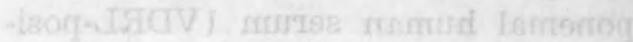

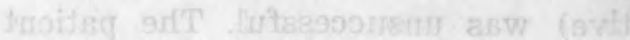

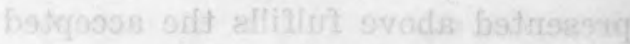

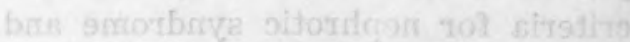

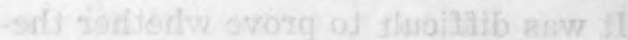

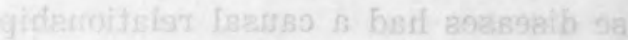

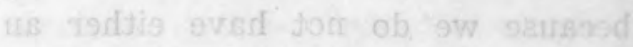

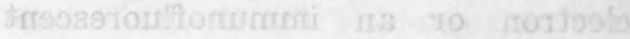

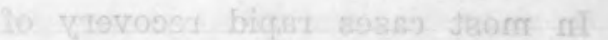

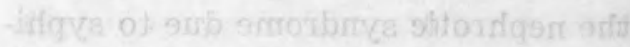

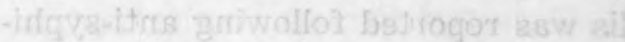

